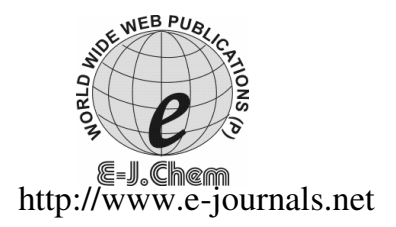

ISSN: 0973-4945; CODEN ECJHAO

E-Journal of Chemistry

2011, 8(3), 1132-1141

\title{
Spectrophotometric Microdetermination of Thorium(IV) and Uranium(VI) with Chrome Azurol-S in Presence of Cationic Surfactant
}

\author{
A. B. UPASE*, A. B. ZADE and P. P. KALBENDE \\ Department of Chemistry, Laxminarayan Institute of Technology \\ R.T.M. Nagpur University, Nagpur, M.S-440010, India \\ *Department of Chemistry, Shri Sitaramji Chaudhary Science College \\ Warud, Dist- Amravati, M.S-444906, India \\ ab_zade18@yahoo.com
}

Received 1 November 2010; Accepted 20 January 2011

\begin{abstract}
Cationic surfactant, cetyldimethylethylammonium bromide (CDMEAB), sensitize the color reactions of Th(IV) and U(VI) with chrome azurol-S(CRAS). Formation of water soluble deeply colored ternary complexes of metal ions show large bathochromic shift. Same stoichiometric composition of ternary complexes with 1:2:4 molar ratio (M-CRASCDMEAB) have been observed for both the metal ions and are responsible for enhancement in molar absorptivities and sensitivities at shifted wavelength. The ternary complexes of thorium(IV) and uranium(VI) exhibit absorption maxima at 640 and $620 \mathrm{~nm}$ with molar absorptivities 85500 and $69600 \mathrm{~L} \cdot \mathrm{mol}^{-1} \cdot \mathrm{cm}^{-2}$ respectively. Beer's law were obeyed in concentration range $0.12-0.185 \mathrm{ppm}$ for $\mathrm{Th}(\mathrm{IV})$ and $0.13-0.162 \mathrm{ppm}$ for $\mathrm{U}(\mathrm{VI})$ in presence of CDMEAB. Conditional formation constants and various analytical parameters have been evaluated and compared the results of binary and ternary complexes. Enhancement in the molar absorptivities in presence of CDMEAB clearly indicated the usefulness of these colored reactions for microdetermination.
\end{abstract}

Keywords: Spectrophotometry, Chrome azurol-S (CRAS), Cetyldimethlethylammonium bromide (CDMEAB), Thorium(Th), Uranium(U), Ternary complexes.

\section{Introduction}

Both thorium and uranium are of great interest as they are used in the production of energy in nuclear reactors. Thorium has not been used extensively as power reactor fuel because it has some inherent limitations in the fuel cycle which ultimately operates on $\mathrm{U}^{233}$. Since, monazite sand possesses thorium of $10-11 \%$ concentration of $\mathrm{ThO}_{2}$ in the amount $2 \times 10^{5}$ tones of thorium and can be extracted satisfactorily from monazite by $\mathrm{NaOH}$ leaching and 
further purified with tertiary butyl phosphate. But the thermal breeding advantages of thorium could not be achieved in aqueous solution because of extreme corrosion problems and complicated decay scheme going from ${ }_{90} \mathrm{Th}^{232} \rightarrow{ }_{92} \mathrm{U}^{233}$ which gives rise to an excessive cost for processing technique and thus provides sufficient justification for abandoning most of thorium development in favor of uranium fuel cycles. Application of fluidized bed technique in gases conversion process for uranium is creating environmental problems. Uranium is more abundant in earth crust than mercury and is present in the same amount as that of tin and molybdenum and is widely distributed. Thorium exists with only one natural isotope $\mathrm{Th}^{232}$ and is not very rare. Most of it is obtained as a byproduct in a process of complex phosphate extraction method of rare earths during the processing of monazite.

Considerable interest has been developed in last few decades for the determination of trace amount of thorium and uranium in environmental sites of energy production in nuclear reactor. This initiated the present investigation for development of simple, convenient and reliable method for microdetermination. Most of the reported methods as discussed below, found to have some limitations for its determination at low concentration and are applicable only at high concentration of metal ions. Number of reagents has been reported for the determination of various metal ions as binary complexes by spectrophotometry however, most of them lack in sensitivity to the extent of their determination when present in very small concentration.

A very few ternary or mixed ligand complexes appear in the literature for their spectrophotometric microdeterminations. Mamedova and coworkers ${ }^{1-3}$ studied the complexation of tungsten(VI), vanadium(V), molybdenum(VI), copper(II) and titanium(IV) with pyrogallol red(PGR) and bromopyrogallol red(BPGR) in presence of cationic surfactant like cetylpyridinium bromide and OP-7. Cationic surfactants, such as cetylpyridinium bromide (CPB), sensitized the color reaction of $\mathrm{Nb}(\mathrm{V})$ with 1-(2-benzothiazolylazo)-2-hydroxy-3naphthoic acid $\left(\mathrm{I}_{\mathrm{a}}\right)$, 5-(benzothiazolylazo)2,5-naphthalenediol $\left(\mathrm{I}_{\mathrm{b}}\right)$, 5-(2-benzothiazolylazo) 8hydroxyquinoline $\left(I_{c}\right)$ and 4-(2- benzothiazolylazo)2,2-biphenyldiol $\left(I_{d}\right)$ reagents ${ }^{4}$.

Rare earths reported to form ternary complexes by Poluektov and coworkers ${ }^{5}$ as 1:2:4 metal- glycinethymol blue- cetrimide with yttrium subgroup elements at an optimum of $\mathrm{pH}$ 7.8-8.5 and with cesium subgroup elements at $\mathrm{pH}$ 9-9.5. Kirrilov and coworkers ${ }^{6}$ have reported the formation of 1:2:4 complex of rare earth with glycinecresol red and cetrimonium ion in an ammonical medium at $\mathrm{pH}$ 8-9 for reading at 616-620 nm to follow Beer's law for $0.04-1.7 \mu \mathrm{g} / \mathrm{mL}$ of rare earth. A 1:2:2 complex of rare earths, eriochrome black $\mathrm{T}$ and diphenylguanidine in an acetate buffer solution for $\mathrm{pH}$ 6.35-6.8 have been introduced by Akhmedli ${ }^{7}$. Some of the rare earth elements with chrome azurol $\mathrm{S}$ in presence of cetyltrimethylammonium bromide and triton X-100 were determined spectrophotometrically ${ }^{8}$. Attempts have been made in the early 70's to improve the sensitivity of some reagents for the microdetermination of rare earths using cationic surfactants like cetyltrimethylammonium bromide and cetylpyridinium bromide ${ }^{9-11}$ by increasing the absorbance of the binary complex resulted into heightened molar absorptivity and sensitivity, which has become a useful tool in microdetermination of metal ions. Rare earth elements by flow injection analysis based on their reaction with xylenol orange in presence of CPB were carried out by spectrophotometric method ${ }^{12}$.

A 1:1:2 ternary complex of neodymium-gallein-cetrimide at $622 \mathrm{~nm}$ have been reported $^{13}$. The surfactant (CPB) sensitized analytical reaction of cerium(IV) with some triphenylformazan derivatives was studied by Ahmed et al. ${ }^{14}$. In spectrophotometric determination of some lanthanides with triphenylmethane dyes such as chrome azurol- S, erichrome cyanine $\mathrm{R}$ and pyrocatechol violet in presence of cetyltrimethylammonium 
bromide, cetylpyridinium bromide and tetradecyldimethyl benzylammonium bromide (zephiramine) have been studied by Jarosz and observed the highest sensitivity of scandium complex with zephiramine and chrome azurol- $S^{15}$. A spectrophotometric reagent 2-hydroxy1-naphthaldehyde- $p$-hydroxybenzoic hydrozone was used for the determination of lanthanum(III) in presence of $\mathrm{CTAB}^{16}$. Neodymium in mixed rare earths with semi-xylenol orange and cetylpyridinium chloride was determined by spectrophotometric method ${ }^{17}$. Ciclopirox olamine was determined via ternary complex with $\mathrm{Tb}$ (III) and EDTA by spectrofluorimetric method ${ }^{18}$. Lanthanum, holmium and manganese in synthetic ceramics, $\left(\mathrm{La}_{(0.8-\mathrm{x})} \mathrm{Ho}_{\mathrm{x}} \mathrm{Sr}_{0.2} \mathrm{MnO}_{3}\right)$, by using chromogenic agent 5-Br-PADAP [2-(5-bromo-2pyridylazo)-5-diethylaminophenol] and triton X-100 as a surfactant were determined by spectrophotometric method ${ }^{19}$.

Both Th(IV) and U(VI) were determined as ternary complexes with methylthymol blue and cetyldimethylethylammonium bromide earlier in our laboratory ${ }^{20}$. A 1:2:4 thoriummethylthymol blue - diphenylguanidine complex was reported by Makoto Otomo ${ }^{21}$. Spectrophotometric determination of uranium(VI) with pyrocatechol violet in surfactant media $^{22}$ and ternary complexes of thorium with 8-hydroxy-5,7-dinitroquinoline and rhodamine- $\mathrm{B}^{23} 5,7$-dibromo- 8 -hydroxyquinoline and rhodamine- $\mathrm{B}^{24}$ have also been reported. Thorium, lanthanum and yttrium in some geological and environmental samples were determined spectrophotometrically by using eriochrome cyanine R (ECR) in presence of surfactant TX-100 and CTAB ${ }^{25}$.

The present study hence was planned to suggest really simple and reasonably good method for determination of these metal ions at low concentration, using the reported reagent chrome azurol-S (CRAS) as a binary complex and sensitizing the reagent with cationic surfactant (CDMEAB) as ternary complexes using spectrophotometer which is still frequently used because of its low cost and simplicity.

\section{Experimental}

All absorbance measurements were carried out by using Hitachi U 2001 spectrophotometer with matched quartz cell with $1.0 \mathrm{~cm}$ thickness. For all spectral studies deionised distilled water was used as a reference solution. The $\mathrm{pH}$ values of these solutions were adjusted using Elico Li-10 pH meter, operated on 220 volts stabilizer with AC mains with glass and calomel electrodes assembly. The $\mathrm{pH}$ scale was standardized and frequently checked with potassium hydrogen phthalate solution of $\mathrm{pH} 4.02$ and borax solution of $\mathrm{pH} 9.20$. Analytical grade hydrochloric acid and sodium hydroxide solutions of suitable concentration were used for $\mathrm{pH}$ adjustment. Chrome azurol-S (CRAS) and cetyldimethylethylammonium bromide (CDMEAB), were supplied by sigma and Aldrich chemical company, USA respectively. Purity of CDMEAB was estimated by using argentometric titration for the determination of bromide ion content ${ }^{26}$. Thorium nitrate and uranyl acetate of analytical grade purity were supplied by British drug house company, England. Stock solutions of CRAS, CDMEAB and metal ions were prepared of strength $1.0 \times 10^{-2} \mathrm{M}$ and subsequently diluted to desired concentrations using double distilled water.

\section{General procedure}

All the experiments were carried out at room temperature of $30 \pm 2{ }^{\circ} \mathrm{C}$. The CDMEAB solution was first added to CRAS solution and kept for equilibration for half an hour. Metal ion solution was then added to dye surfactant solution and again kept for half an hour to reach complete equilibrium. This order of mixing the solutions was maintained throughout the investigation. 


\section{Results and Discussion}

\section{Absorption spectra}

\section{Study of absorption spectra of CRAS in absence and presence of CDMEAB}

Absorption spectra of CRAS shows wavelength of maximum absorption $\left(\lambda_{\max }\right)$ at $480 \mathrm{~nm}$ in $\mathrm{pH}$ range $1.0-2.0$, at $510 \mathrm{~nm}$ in $\mathrm{pH} 3.0-4.5$, at $430 \mathrm{~nm}$ in $\mathrm{pH}$ range $5.5-11.0$ and; $630 \mathrm{~nm}$ at $\mathrm{pH} 11.0$ and above. The variations in absorbance maximum could be interpreted in terms of increasing dissociation of protons from CRAS. However, absorption spectra of CRAS in presence of CDMEAB showed the absorption maxima at $420 \mathrm{~nm}$ in $\mathrm{pH} 5.0-10.0$, at $530 \mathrm{~nm}$ in $\mathrm{pH}$ range 1.0-4.0. No notable shifts in $\lambda_{\max }$ of CRAS have been observed in $\mathrm{pH}$ range 5.5-12.0 in presence of CDMEAB. These spectral changes indicate an early dissociation of proton in presence of CDMEAB takes place as expected theoretically and shows the ionic interaction between anionic CRAS and cationic CDMEAB. This ionic interaction results into decrease in $\mathrm{pKa}$ values with decrease in absorbance values as reported in the literature.

Effect of surfactant concentration on absorbance of CRAS at various wavelength in acidic range shows maximum decolorizing effect at the minimal ratio of 1:2 (CRAS:CDMEAB). When this ratio has been reached, the absorbance of CRAS remains unchanged even if fivefold excess of CDMEAB have been added. Thus, the CRAS in presence of CDMEAB can be represented as $\left[\mathrm{CRAS}(\mathrm{CDMEAB})_{2}\right.$ ] as a modified reagent as reported earlier ${ }^{26}$.

\section{Study of absorption spectra of binary and ternary complexes}

Spectral study of binary and ternary complexes show $\lambda_{\max }$ at 590 and $640 \mathrm{~nm}$ for Th(IV) and at 620 and $630 \mathrm{~nm}$ for $\mathrm{U}(\mathrm{VI})$ respectively in acidic range. Plots of comparative absorption spectra at $\mathrm{pH} 6.5$ for $\mathrm{Th}(\mathrm{IV})$ and at $\mathrm{pH} 5.0$ for $\mathrm{U}(\mathrm{VI})$ where the maximum difference in absorbance have been observed between binary and ternary complexes as shown in Figures 1 and 2 respectively.

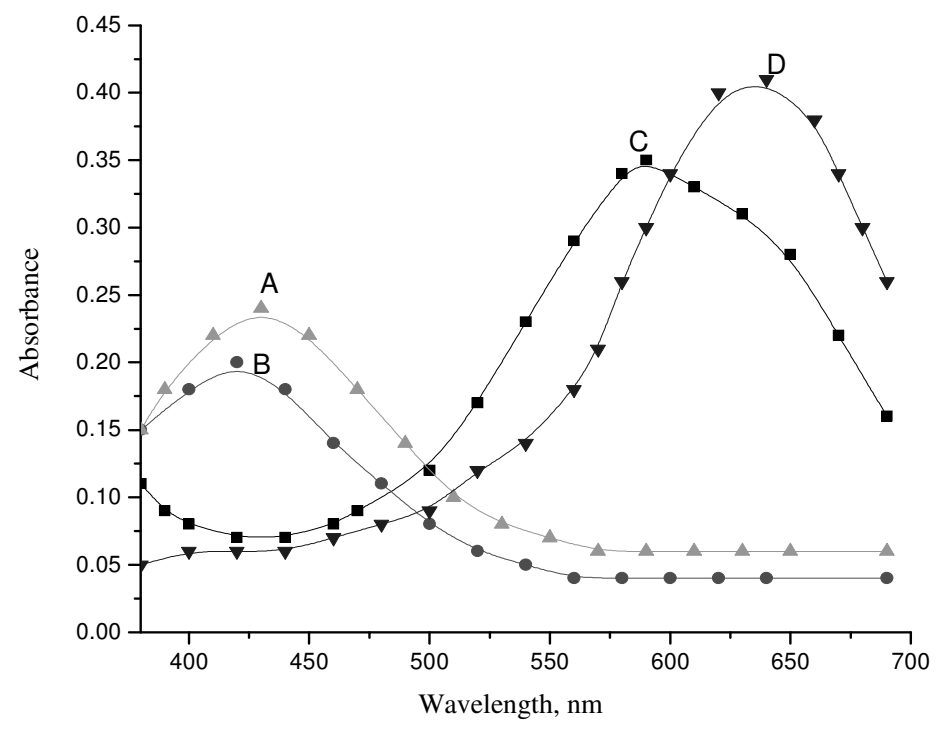

Figure 1. Absorption spectra of $\mathrm{Th}(\mathrm{IV})$ at $\mathrm{pH}$ 6.5, A) CRAS-(Reagent); B) CRASCDMEAB-(Modified reagent); C) CRAS-Th(IV) at(pH 4.5)-(Binary complex) and D) CRAS-CDMEAB-Th(IV)-(Ternary complex) 


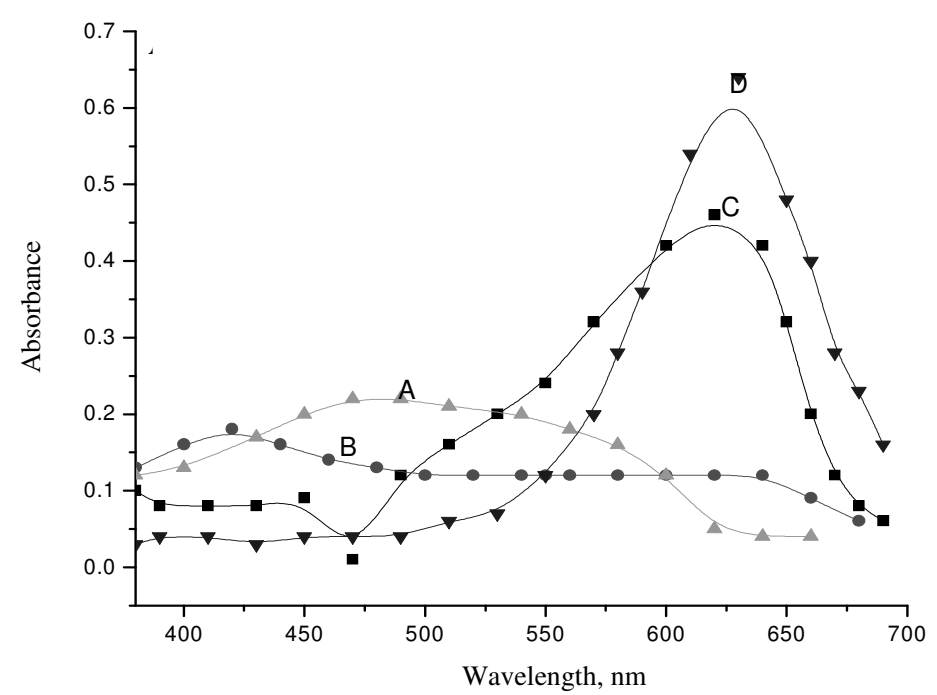

Figure 2. Absorption spectra of U(VI) at $\mathrm{pH} 5$, A) CRAS-(Reagent); B) CRAS-CDMEAB(Modified reagent); C) CRAS-U(VI)-(Binary complex) and D) CRAS-CDMEAB-U(VI)(Ternary complex)

Absorption spectra of CRAS alone as indicated by curve A in Figure 1 and 2 shows $\lambda_{\max }$ $430 \mathrm{~nm}$ at $\mathrm{pH} 6.5$ and $470 \mathrm{~nm}$ at 5.0 respectively. Absorption spectra of CRAS in presence of fivefold excess of CDMEAB as represented by curve B indicates considerable decrease in absorbance values. Curve $\mathrm{C}$ in Figure 1 shows absorption spectra of Th(IV) complex of CRAS indicates the binary complexation with a shift in $\lambda_{\max }$ of CRAS from 420 to $590 \mathrm{~nm}$. Precipitation of $\mathrm{Th}(\mathrm{IV})$ has been observed above $\mathrm{pH} 5.0$, however there was no precipitation up to $\mathrm{pH} 7.0$ in presence of CDMEAB. Curve-D in Figure 1 represents ternary complexation of $\mathrm{Th}(\mathrm{IV})$ with CRAS in presence of CDMEAB, which shows maximum absorption at $640 \mathrm{~nm}$ with a considerable increase in absorbance and thus a bathochromic shift of $50 \mathrm{~nm}$ have been observed.

In Figure 2 curve $\mathrm{C}$ represents absorption spectra of U(VI) complex with CRAS in absence of CDMEAB which shows $\lambda_{\max }$ at $620 \mathrm{~nm}$ indicating binary complex formation. However, absorption spectra of U(VI) complex with CRAS in presence of fivefold excess of CDMEAB as indicated by curve-A shows maximum absorption at $630 \mathrm{~nm}$ with increase in absorbance and thus a bathochromic shift of $10 \mathrm{~nm}$ has been observed.

Thus, the use of CDMEAB as a cationic surfactant has been found to most effective in improving absorbance with heightened molar absorptivity resulting into formation of intense colored ternary complexes with a bathochromic shift of 50 and $10 \mathrm{~nm}$ for ternary complexes of Th(IV) and U(VI) respectively.

\section{Effect of $p H$}

In Figures 3 and 4, curve-C is a plot of variations of $\lambda_{\max }$ with the change in $\mathrm{pH}$ of CRAS. Initially the $\lambda_{\max }$ of CRAS remains constant at $510 \mathrm{~nm}$ in $\mathrm{pH}$ range $2.5-4.0$, it gradually decreases to $430 \mathrm{~nm}$ in $\mathrm{pH}$ range 4.0-5.0 and remains constant at $430 \mathrm{~nm}$ in $\mathrm{pH}$ range 5.0-7.0. In Figure 3 and 4, curve-D is a plot of variations of $\lambda_{\max }$ with change in $\mathrm{pH}$ of CRAS in presence of CDMEAB. The $\lambda_{\max }$ Shifts from 510 to $530 \mathrm{~nm}$ in $\mathrm{pH}$ range $2.5-3.5$, it gradually decreases from 530 to $420 \mathrm{~nm}$ in $\mathrm{pH}$ range 3.5-5.0 and remains constant at $420 \mathrm{~nm}$ in $\mathrm{pH}$ range 5.0-7.0. 
In $\mathrm{pH}$ range $2.5-3.5, \lambda_{\max }$ of $\mathrm{Th}(\mathrm{VI})$ complex in presence of CDMEAB gradually decreases from $650-640 \mathrm{~nm}$ and remains constant at $640 \mathrm{~nm}$ up to $\mathrm{pH} 7.0$ is represented by curve $\mathrm{B}$ in Figure 3. However binary complex of Th(IV) shows $\lambda_{\max }$ at $590 \mathrm{~nm}$ up to $\mathrm{pH} 4.5$ above which precipitation of the complex has been observed. Thus a bathochromic Shift of $50 \mathrm{~nm}$ in the formation of ternary complex in wider $\mathrm{pH}$ range in presence of CDMEAB has been observed.

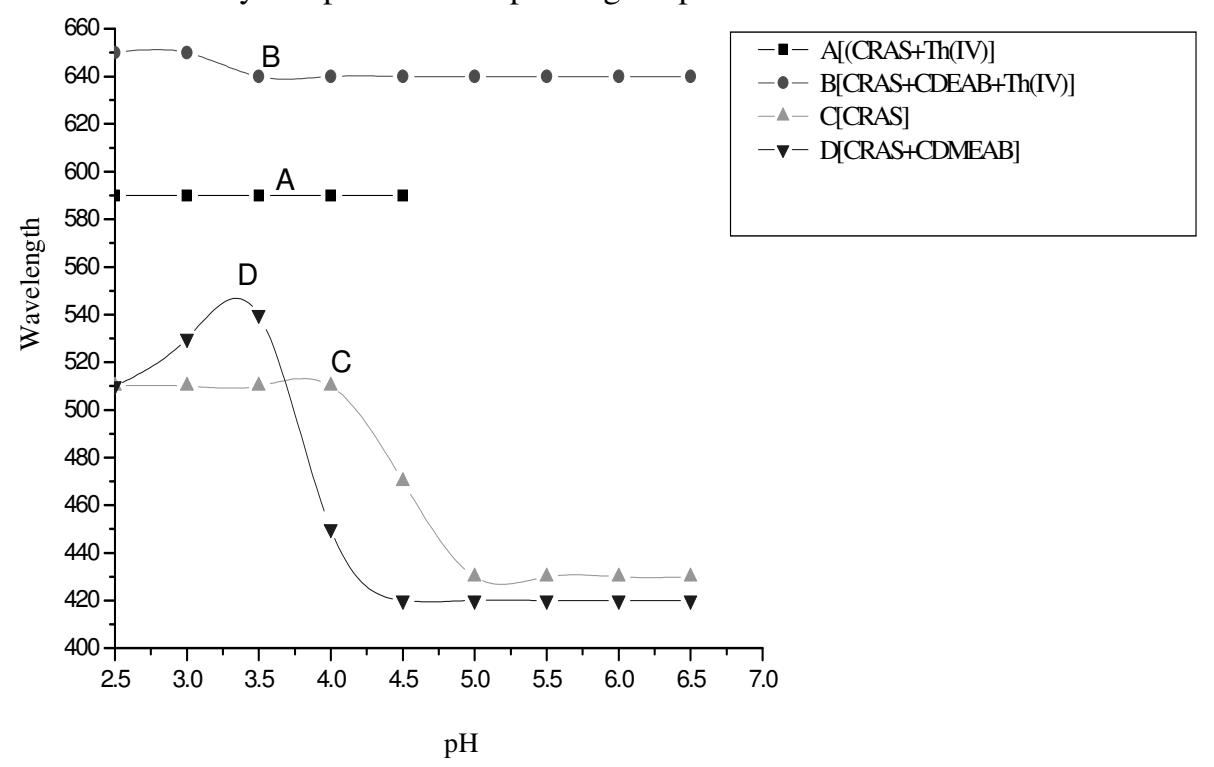

Figure 3. Variations in $\lambda_{\max }$ with changes in the $\mathrm{pH}$ of: A) [CRAS+Th(IV)]-(Binary complex); B) [CRAS+CDMEAB+Th(IV)]-(Ternary complex); C) [CRAS]-(Reagent) and $\mathrm{D}$ [CRAS+CDMEAB]-(Modified reagent)

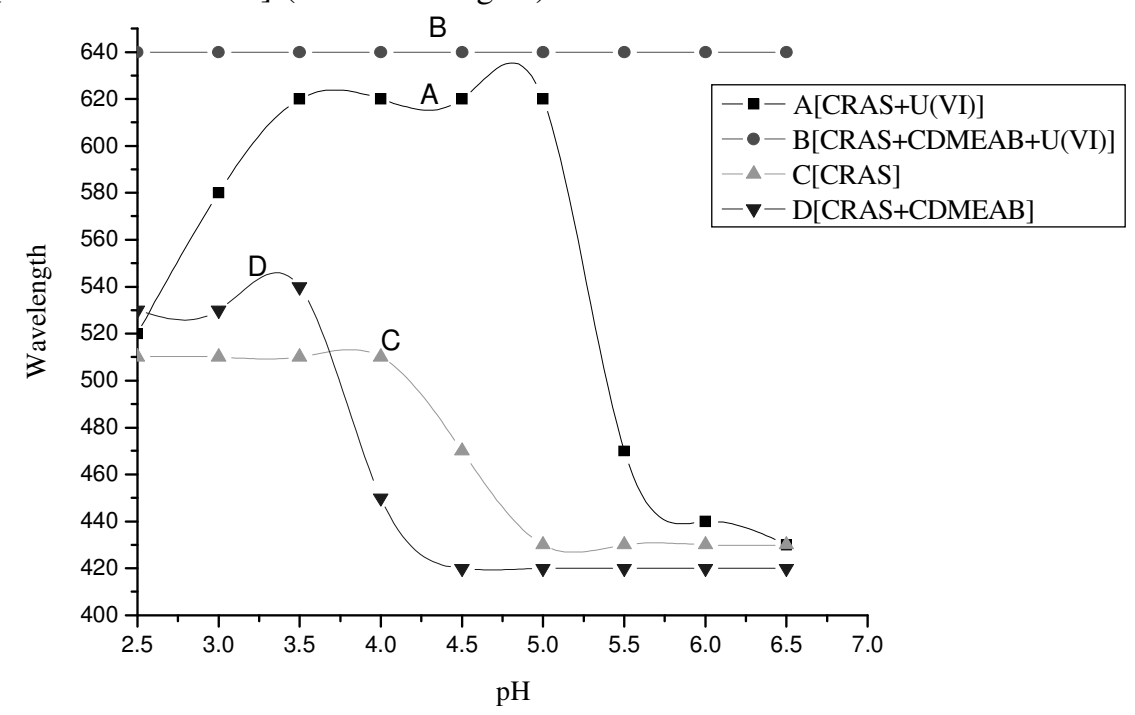

Figure 4. Variations in $\lambda_{\max }$ with changes in the $\mathrm{pH}$ of: $\left.\mathrm{A}\right)[\mathrm{CRAS}+\mathrm{U}(\mathrm{VI})]-(\mathrm{Binary}$ complex); B) [CRAS+CDMEAB+ U(VI)]-(Ternary complex); C) [CRAS]-(Reagent) and D) $[$ CRAS+CDMEAB]-(Modified reagent) 
In $\mathrm{pH}$ range 2.5-7.0, $\lambda_{\max }$ of $\mathrm{U}(\mathrm{IV})$ complex in presence of CDMEAB remains constant at $640 \mathrm{~nm}$ and is represented by curve B in Figure 4. Binary complex of U(VI) shows $\lambda_{\max }$ at 620 $\mathrm{nm}$ in the $\mathrm{pH}$ range 3.5-5.0. It gradually increases from $520-620 \mathrm{~nm}$ in the $\mathrm{pH}$ range $2.5-3.5$ and decreases from $620 \mathrm{~nm}$ to $430 \mathrm{~nm}$ in the $\mathrm{pH}$ range 5.0-6.0. Thus a bathochromic shift of $20 \mathrm{~nm}$ in the formation of ternary complex has been observed in presence of CDMEAB. The $\mathrm{pH}$ range of stability of constant wavelength have been found to be 2.5-4.5 for binary complex and 3.5-6.5 for ternary complex of Th(IV) in absence and presence of CDMEAB respectively. The $\mathrm{pH}$ range of stability of constant wavelength have been found to be 3.5-5.0 for binary complex and 2.5-7.0 for ternary complex of $\mathrm{U}(\mathrm{VI})$ in absence and presence of $\mathrm{CDMEAB}$ respectively.

Variation of absorbance with change in $\mathrm{pH}$ of complexes in presence of CDMEAB at $\lambda_{\max }$ $640 \mathrm{~nm}$ for Th(IV) and $630 \mathrm{~nm}$ for U(IV) is represented in Figure 5. Absorbance of Th(VI) complex in presence of CDMEAB at $640 \mathrm{~nm}$ increases in $\mathrm{pH}$ range 3.0-3.5 and remains constant at $0.420 \mathrm{in} \mathrm{pH}$ range 3.5-6.5 and it decreases in $\mathrm{pH}$ range 6.5-7.0. Similarly absorbance of U(VI) complex of CRAS in presence of CDMEAB at $640 \mathrm{~nm}$ increases in $\mathrm{pH}$ range 3.0-4.0 and remains constant at $0.60 \mathrm{in} \mathrm{pH}$ range 4.0-6.0 and it again decreases in $\mathrm{pH}$ range 6.0-7.0.

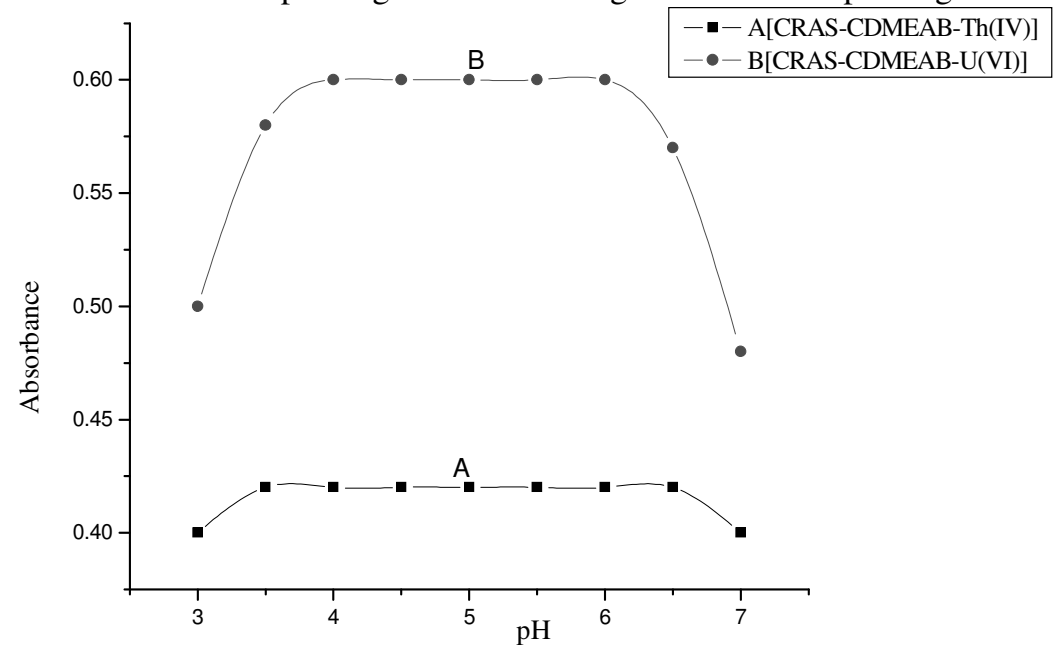

Figure 5. Variations in absorbance at the $\lambda_{\max }$ with changes in the $\mathrm{pH}$ of: A) $\lambda_{\max }, 640 \mathrm{~nm}$ of CRAS-CDMEAB-Th(IV); B) $\lambda_{\max }, 640 \mathrm{~nm}$ of CRAS-CDMEAB-U(VI)

Thus optimum $\mathrm{pH}$ range of stability of complex formation of constant absorbance have been found to be 3.5-6.5 at the $\lambda_{\max } 640$ for Th(IV) and 4.0-6.0 at the $\lambda_{\max } 640 \mathrm{~nm}$ for U(VI). Thus the complexation in presence of CDMEAB takes place in wider $\mathrm{pH}$ range with increase in absorbance values as compared to binary complexes indicating sensitization of the reagent in presence of cationic surfactant which can be explored for the microdetermination of metal ions understudy when present in small concentration and undetectable by binary complexation.

\section{Composition of complexes}

The composition of binary and ternary complexes were studied by Job's method of continuous variation $^{27}$ and further confirmed by mole ratio method and found to be 1:2 for Th(IV) to CRAS and 1:1 for U(VI) to CRAS. However, the molar ratio of ternary complexes of $\mathrm{Th}(\mathrm{IV})$ and $\mathrm{U}(\mathrm{VI})$ with CRAS was found to 1:2 in presence of CDMEAB. Stoichiometric composition of ternary complexes as Th(IV)-CRASCDMEAB and U(VI)-CRAS-CDMEAB may be expressed as 1:2:4. 


\section{$\mathrm{M}^{+2}\left[\mathrm{CRAS}(\mathrm{CDEAB})_{2}\right] \rightarrow \mathrm{M}\left[\mathrm{CRAS}(\mathrm{CDMEAB})_{2}\right]_{2}$ Stability constant of complexes}

The values of $\log \mathrm{K}\left\{\right.$ where, $\left.\mathrm{K}=\left[\mathrm{ML}_{2}\right] /[\mathrm{ML}][\mathrm{L}]\right\}$ i.e. stability constants have been calculated from the curves of Job's method of continuous variations and mole ratio method and are given in Table 1. The values for particular metal in presence of CDMEAB are higher in presence than in absence which shows that the complexes are stabilized in presence of cationic surfactant CDMEAB.

Table 1. Composition and $\log \mathrm{K}$ values of thorium and uranyl chelates of CRAS in absence and presence of CDMEAB

\begin{tabular}{ccccccc}
\hline $\begin{array}{c}\text { Metal } \\
\text { ions }\end{array}$ & $\begin{array}{c}\text { Study in A-absence } \\
\text { B-presence of } \\
\text { CDMEAB }\end{array}$ & $\mathrm{pH}$ & $\begin{array}{c}\text { Wavelength, } \\
\text { nm }\end{array}$ & $\begin{array}{c}\text { Composition } \\
\text { M:R or M:(R:S) }\end{array}$ & $\begin{array}{c}\text { Jog K values by } \\
\text { method }\end{array}$ & $\begin{array}{c}\text { Mole ratio } \\
\text { method }\end{array}$ \\
\hline Th(IV) & A & 4.5 & 590 & $1: 2$ & 8.90 & 8.90 \\
Th(IV) & B & 6.5 & 640 & $1: 2: 4$ & 10.02 & 10.01 \\
U(VI) & A & 5.0 & 620 & $1: 1$ & 5.46 & 5.45 \\
U(VI) & B & 5.0 & 640 & $1: 2: 4$ & 9.90 & 9.92 \\
\hline
\end{tabular}

Analytical applications of complexes of Th(IV) and U(VI) in presence of CDMEAB

Formation of intense colored ternary complexes in presence of CDMEAB with high absorbance values at shifted wavelength in wider $\mathrm{pH}$ range have been observed in the present investigation resulting into higher molar absorptivity which has been used as a useful property for microdetermination of metal ions understudy. Various analytical parameters have been studied and compared with the binary complexes to prove the sensitization and importance of the cationic CDMEAB.

\section{Rate of color formation and stability of color at room temperature}

Highly soluble colored complexes in presence of CDMEAB were formed instantaneously at ambient temperature $\left(25 \pm 1^{\circ} \mathrm{C}\right)$. On increasing temperature up to $60{ }^{\circ} \mathrm{C}$, no change in the absorbance values has been observed. The absorbance of complexes remains constant for at least $48 \mathrm{hrs}$ then decreases gradually.

\section{Effect of reagent concentration}

Maximum color formation have been observed when the solution contained three fold for $\mathrm{Th}(\mathrm{IV})$ and two fold for $\mathrm{U}(\mathrm{VI})$, molar excess of modified reagent with respect to metal ion solution. However, in absence of CDMEAB the amounts of CRAS required for complete color formation were found to be five and four times than those of Th(IV) and U(VI) metal ions concentration respectively.

\section{Beer's law and effective photometric ranges}

By varying metal ion concentration CRAS ( $2 \mathrm{~mL}$ of $\left.5.0 \times 10^{-4} \mathrm{M}\right)$ and measuring the absorbance at the $\mathrm{pH}$ and wavelength of study chosen for respective metal ion, the linearity between the absorbance of chelates and metal ions in presence of CDMEAB has been carried out. The Beer's law range as well as effective photometric range for both $\mathrm{Th}(\mathrm{IV})$ and U(VI) metal ions has been calculated from these data and the Ringbom plot $^{28}$ in absence and presence of CDMEAB. The values are recorded in Table 2. 
Table 2. Photometric determination of Th(IV) and U(VI) metal ions with CRAS in absence and presence of $\mathrm{CDMEAB}$

\begin{tabular}{cccccc}
\hline $\begin{array}{c}\text { Metal } \\
\text { ions }\end{array}$ & $\begin{array}{c}\text { Study } \\
\text { with CDMEAB }\end{array}$ & $\begin{array}{c}\text { Beer's law } \\
\text { range, ppm }\end{array}$ & $\begin{array}{c}\text { Effective } \\
\text { photometric } \\
\text { range, ppm }\end{array}$ & $\begin{array}{c}\text { Sandell's } \\
\text { sensitivity, } \\
\mu \mathrm{g} / \mathrm{cm}^{2}\end{array}$ & $\begin{array}{c}\text { Molar } \\
\text { absorptivity }\end{array}$ \\
\hline $\mathrm{Th}(\mathrm{IV})$ & $\mathrm{A}$ & $0.23-2.08$ & $0.92-1.62$ & 0.0073 & 31300 \\
$\mathrm{Th}(\mathrm{IV})$ & $\mathrm{B}$ & $0.12-1.85$ & $0.46-1.39$ & 0.0029 & 85500 \\
$\mathrm{U}(\mathrm{VI})$ & $\mathrm{A}$ & $0.27-2.16$ & $0.81-1.90$ & 0.0089 & 35200 \\
$\mathrm{U}(\mathrm{VI})$ & $\mathrm{B}$ & $0.13-1.62$ & $0.27-1.62$ & 0.0034 & 69600 \\
\hline
\end{tabular}

$A$-Absence and B-Presence of CDMEAB

The average values of molar absorptivities and Sandell's sensitivities ${ }^{29}$ (against 0.01 absorbance) calculated in absence and presence of fivefold excess of CDMEAB for each complex have been shown in Table 2 which shows considerable increase in sensitivity of these ternary complex forming reactions in presence of CDMEAB as compared to binary complexes indicating the usefulness and the importance in microdetermination.

Procedure for microdetermination of individual Th(IV)and U(VI)

Solution containing 30 to $70 \mu \mathrm{g}$ of metal ion was adjusted to 6.5 for $\mathrm{Th}(\mathrm{IV})$ and 5.0 for U(IV) ions. The modified CRAS was prepared by adding about five fold excess of CDMEAB solution to CRAS solution and keeping it for half an hour for equilibration $2 \mathrm{~mL}$ of this modified CRAS solution of the same $\mathrm{pH}$ was added to above metal ion solution. The volume was made to $50 \mathrm{~mL}$ with distilled water of same $\mathrm{pH}$. The absorbances were recorded at $640 \mathrm{~nm}$ for $\mathrm{Th}(\mathrm{IV})$ and $\mathrm{U}(\mathrm{VI})$ metal ions against reagent blank. The absorbances of these unknown solutions were then compared with calibration curves obtained under similar condition. Results of seven determinations by taking $69.60 \mu \mathrm{g} / 50 \mathrm{~mL} \mathrm{Th}(\mathrm{IV})$ ions and $67.50 \mu \mathrm{g} / 50 \mathrm{~mL}$ $\mathrm{U}(\mathrm{VI})$ ions showed standard average deviation of 0.025 and 0.027 respectively (Table 3 ).

Table 3. Microdetermination of individual metal ions

\begin{tabular}{cccc}
\hline Metal ions & $\begin{array}{c}\text { Amount taken, } \\
\mu \mathrm{g} / 50 \mathrm{~mL}\end{array}$ & $\begin{array}{c}\text { Amount found } \\
\mu \mathrm{g} / 50 \mathrm{~mL}\end{array}$ & $\begin{array}{c}\text { Standard average } \\
\text { deviation }\end{array}$ \\
\hline $\mathrm{Th}(\mathrm{IV})$ & 69.60 & 69.77 & 0.025 \\
$\mathrm{U}(\mathrm{VI})$ & 67.50 & 67.65 & 0.027 \\
\hline
\end{tabular}

Effect of foreign ions

It was observed that $\mathrm{Cu}^{2+}$ and $\mathrm{In}^{3+}$ interfere at all concentrations for both the metal ions under study. Polycarboxylate anion such as oxalate and EDTA (Ethylenediamine tetraacetic acid) give negative errors.

\section{Conclusion}

The sensitization of CRAS has taken place in presence of cationic CDMEAB ensuing into the formation of intense colored ternary complexes with bathochromic shift and increase in absorbance values at shifted wavelength resulted into the formation of heighten sensitivity and absorptivity in wider $\mathrm{pH}$ range. The complexes between CRAS and both the metals under study in the presence of CDMEAB are very stable and more sensitive in presence than in absence of surfactant. This developed method for the microdetermination of $\mathrm{Th}(\mathrm{IV})$ and $\mathrm{U}(\mathrm{VI})$ is inexpensive involves the use of readily available reagents, allows rapid determination at low operating costs and can be used in a simple laboratory $\mathrm{pH}$ meter and spectrophotometer. The procedure showed simplicity, adequate sensitivity and having low limit of detection with comparatively very few interferences and more accurate than the other methods reported earlier. 


\section{Acknowledgment}

Authors are thankful to Prof. R. B. Mankar, Formar Director of Laxminarayan Institute of Technology, R.T.M. Nagpur University, Nagpur and presently Vice Chancellor of Dr. Babasaheb Ambedkar Technical University, Lonere (MS) for constant encouragement and support.

\section{References}

1. Mamedova A M, Ivanov V M and Akhmedov S A, Moscow Univer Chem Bull., 2004, 45(2), 117.

2. Mamedova A M and Ivanov V M, Anal Chem Moscow Russia, 2006, 61(3), 242.

3. Ivanov V M, Mamedova A M and Akhmedov S A, Moscow Univer Chem Bull., 2003, 44(5), 304.

4. Alaa Amin S, Microchem J., 2000, 65, 261.

5. Kirilov A I, Makarenko O P, Poluektov N S, Lauer R S and Shaulina L P, Zh Anal Khim., 1973, 28, 1618-1621.

6. Kirrilov A I, Shaulina L P, Makarenko O P and Poluektov N S, Zh Anal Khim., 1974, 29, 1648-1650.

7. Akhmedli M K, Granovaskaya P B and Neimatova R A, Zh Anal Khim., 1973, 28(2), 278-284.

8. Preisler, Jan-Jancar, Ludek- Sommer, Lumir, Collection of Czechoslovak Chemical Communications, 2009, 58, 1495-1508.

9. Vekhande C R and Munshi K N, Indian J Chem., 1976, 14(A), 189.

10. Otomo M and Wakamatsu Y, Jap Anal., 1968, 17, 764.

11. Svoboda V and Chromy V, Talanta, 1966, 13, 257.

12. Havel J, Moreno C, Hardlic ka A and Valiente M, Talanta, 1994, 41, 1251.

13. Poluektov N S, Lauer R S and Ovchar L A, Zh Anal Khim., 1973, 28(8), 1490-1494.

14. Ahmed I S, Amin A S, Issa Y M, Spectrochimica Acta A, 2006, 64(1), 246-250.

15. Jarosz M and Marczenko, Anal Chem Acta, 1984, 159, 309

16. Chaudhary Govinda, Mohan Reddy K P P R and Reddy Raveendra, Indian J Chem., 2008, 47(A), 1381-1383.

17. Nai-Xing Wang, Talanta, 1991, 38(7), 711.

18. Mohammad Ibrahim Walash, Mohammad Salem Rizk, Manal Ibrahim Eid and Mona El Sayed Fathy, Acta Pharm., 2006, 56, 431-440.

19. Ferreyra R E, Camina J M, Marchevskaya E and Luco J M, Fresenius J Anal Chem., 2000, 368, 595-600.

20. Upase A B and Zade A B, J Indian Chem Soc., 2005, 82(9), 853-856.

21. Makoto Otomo, J Chem Soc Jap Pure Chem Sect., 1968, 89, 503-506.

22. Chan-il Park, Hua- Zi Huang and Ki-Won Cha, Bull Korean Chem Soc., 2001, 22(1), 84-86.

23. Granovskii Yu V, Runov V K, Tishchenko I S and Golovina A P, Zh Anal Khim., 1974, 29(10), 1959-1963.

24. Mischenko V T and Zavarina T V, Zh Chim Anal (Paris), 1970, 25, 1533-1538.

25. Abdallah A M, Kabil M A, Akl M A and Ismael D S, J Iranian Chem Soc., 2004, 1, 79.

26. Zade A B and Munshi K N, Surfactant in Solution, Plenum Press, New York, 1989, 9, 261.

27. Job P, Ann Chim., 9, 113; Chem Abstr., 1928, 22, 2120.

28. Ringbom A Z, Anal Chem., 1939,115, 332.

29. Sandell E B, Colorimetric Determination of Trace Metals $3^{\text {rd }}$ Edn., Interscience Publishers Inc., New York, 1959, 568. 


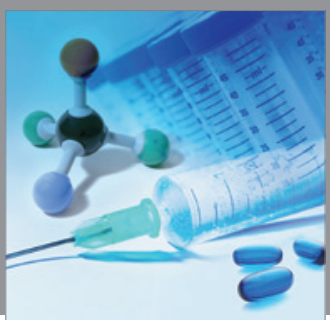

International Journal of

Medicinal Chemistry

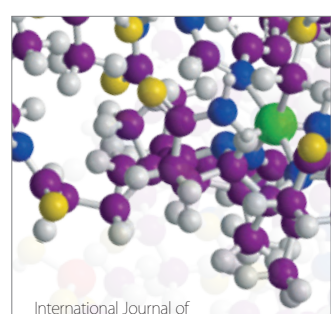

Carbohydrate Chemistry

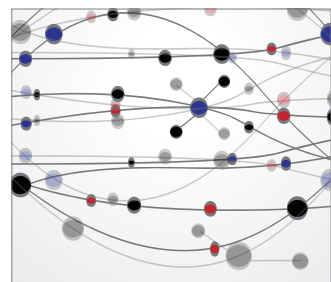

The Scientific World Journal
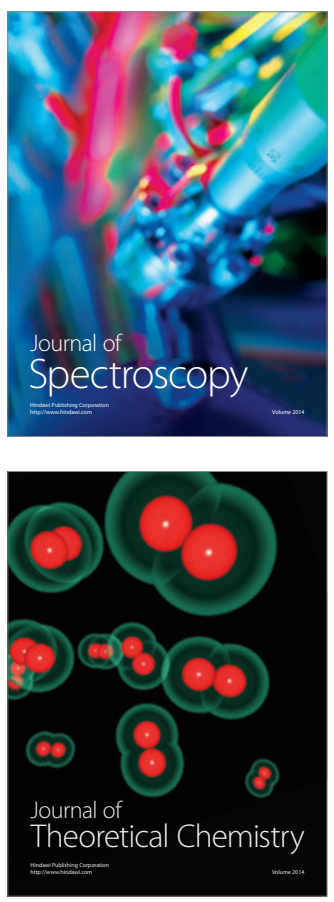
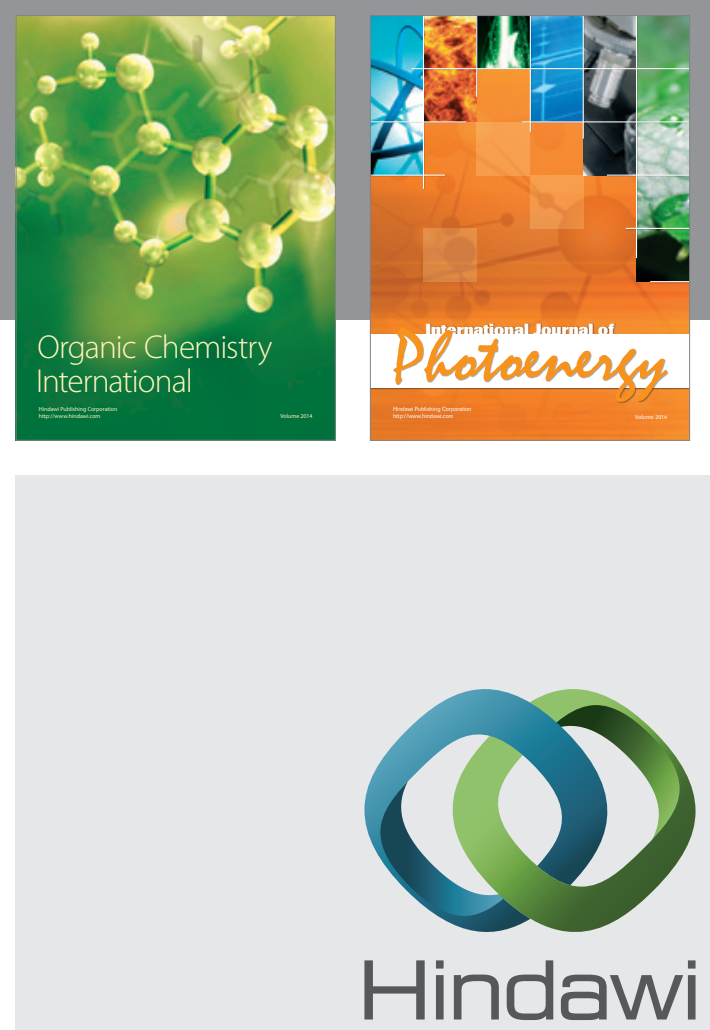

Submit your manuscripts at

http://www.hindawi.com
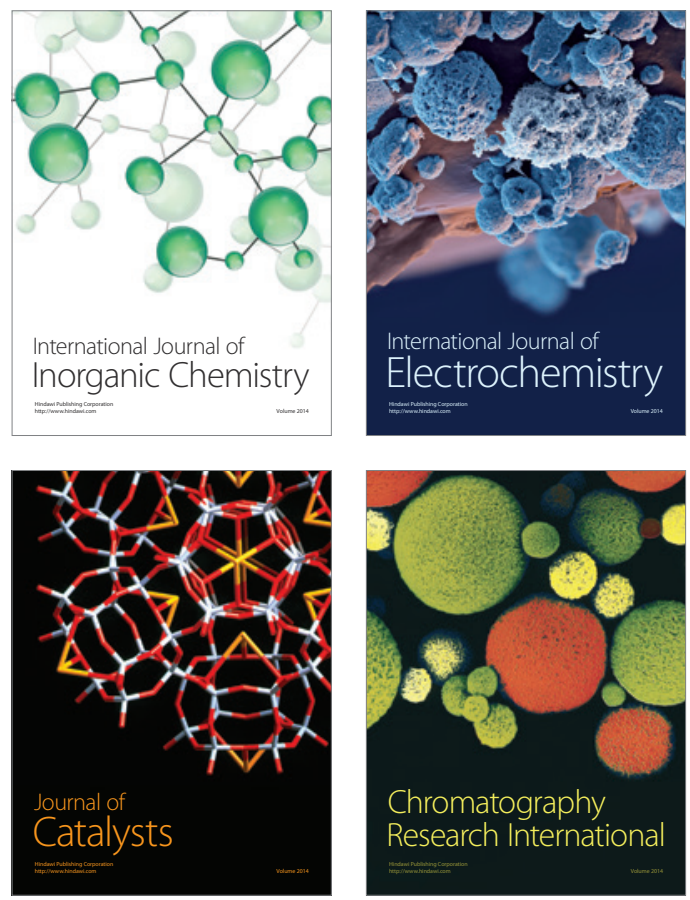
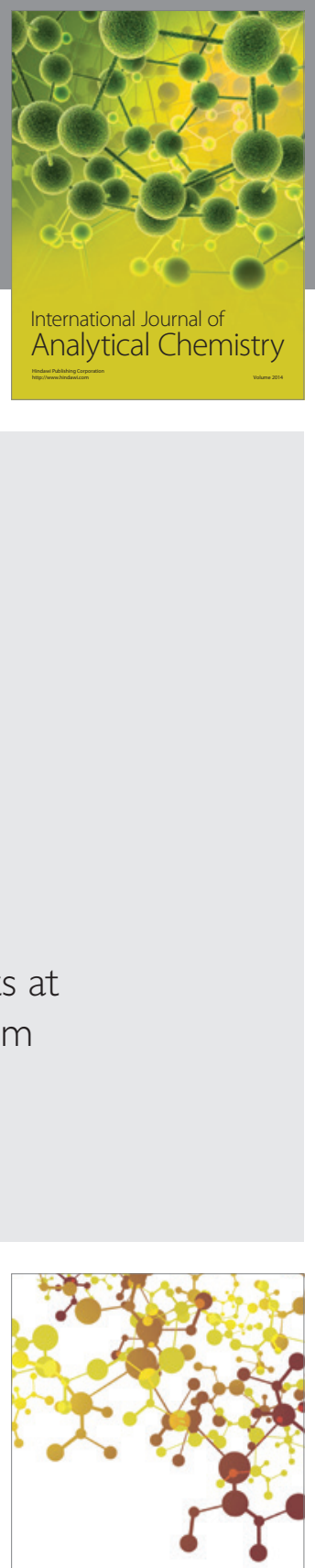

Journal of

Applied Chemistry
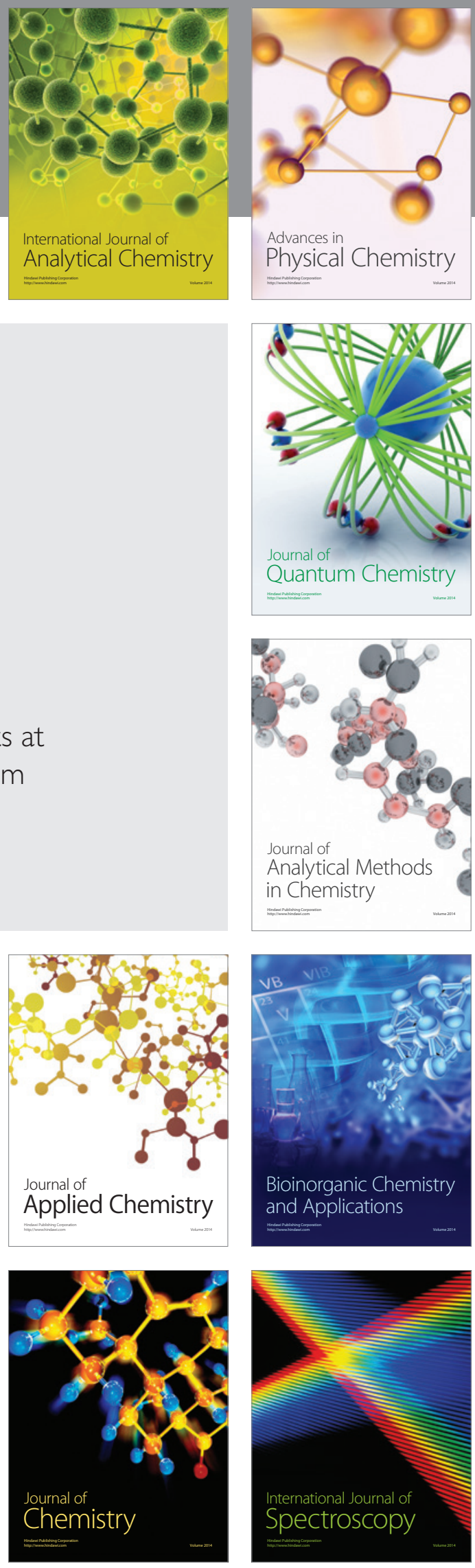